Published in Biochemical Society Transactions 33: 1186-1188, 2005

\title{
Saccharomyces cerevisiae, a model to study sterol uptake and transport in eukaryotes
}

\author{
Sonja Reiner ${ }^{1}$, Delphine Micolod ${ }^{2}$, and Roger Schneiter ${ }^{2 *}$ \\ ${ }^{1}$ Institute of Biochemistry, Graz University of Technology, 8010 Graz, Austria; \\ ${ }^{2}$ Department of Medicine, Division of Biochemistry, University of Fribourg, 1700 \\ Fribourg, Switzerland
}

Running title: sterol uptake and transport in yeast

Key words: cholesterol, anaerobiosis, respiration, membrane transport, ABC transporter, Saccharomyces cerevisiae

*Corresponding author: Roger Schneiter, University of Fribourg, Department of Medicine, Division of Biochemistry, Chemin du Musée 5, CH-1700 Fribourg, Switzerland; Phone: +41 26300 8654, Fax: +41 26300 9735, Email: roger.schneiter@unifr.ch 


\begin{abstract}
The molecular mechanisms that govern intracellular transport of sterols in eukaryotic cells are only poorly understood. Saccharomyces cerevisiae is a facultative anaerobic organism that requires supplementation with unsaturated fatty acids and sterols to grow in the absence of oxygen, as the synthesis of these lipids requires molecular oxygen. The fact that yeast grows well under anaerobic conditions indicates that lipid uptake is rapid and efficient. To identify components in this lipid uptake and transport pathway, we screened the yeast mutant collection for genes that are essential under anaerobic conditions. Of the $\sim 4800$ nonessential genes represented in the mutant collection, 37 were required for growth under anaerobic conditions. Uptake assays using radiolabeled cholesterol revealed that 16 of these genes are required for cholesterol uptake/transport and esterification. Further characterization of the precise role of these genes is likely to advance our understanding of this elusive pathway in yeast and may prove to be relevant to understand sterol homeostasis in higher eukaryotic cells.
\end{abstract}




\section{INTRODUCTION}

Sterols are important lipid components of eukaryotic membranes that determine many membrane characteristics and are required for polar sorting events during vesicle transport in animal, plant, and fungal cells [1-3].

Due to the importance of cholesterol in various cell functions, it is crucial that its levels and intracellular distribution are tightly controlled (for review see [4-6]). Cholesterol is synthesized in the endoplasmic reticulum and subsequently transported to the plasma membrane, which harbors $\sim 90 \%$ of the free sterol pool of the cell [7]. The nature of this transport process is poorly understood but may involve both vesicular and non-vesicular components. Delivery of newly synthesized cholesterol to the plasma membrane is ATP-dependent, but only partially sensitive to brefeldin A [8-11].

Mammalian cells take up exogenous cholesterol by receptor-mediated endocytosis of low-density lipoproteins (LDL) [12]. Once delivered to late endosomes or lysosomes, LDL-derived cholesteryl esters are hydrolyzed, and free cholesterol is rapidly cycled back to the plasma membrane and/or the endoplasmic reticulum for esterification. Maintenance of the cycle between free and esterified sterols thus relies on a bidirectional transport of sterols between the endoplasmic reticulum and the plasma membrane and/or an endocytic compartment [13-18]. The molecular nature of this cycle is poorly understood. Movement of cholesterol from the plasma membrane to the endoplasmic reticulum of mammalian cells is inhibited by hydrophobic amines, progesterone, disruption of the cytoskeleton or that of the acidic compartments, but not by ATP depletion [19-22]. The cholesterol transport cycle is interrupted in certain lipid storage diseases. Most notably in Niemann-Pick type C1 disease, where cholesterol accumulates in an endosomal compartment, or in atherosclerotic 
macrophages, where an excess of free sterol in the endoplasmic reticulum induces apoptosis [23-26].

\section{Sterol uptake and transport in yeast}

Yeast is a valuable model organism to characterize basic cellular processes that are conserved in all eukaryotic cells. S. cerevisiae has been established as a model organism to study intracellular sterol transport and homeostasis by Sturley and coworkers $[27,28]$. The basic steps of sterol synthesis in yeast are the same as in higher eukaryotic cells, even though this fungus synthesizes ergosterol instead of cholesterol [29]. As in mammalian cells, ergosterol is synthesized in the endoplasmic reticulum, transported by a poorly characterized mechanism to the plasma membrane, and excess of free sterol is esterified by two acyl CoA:cholesterol acyltransferases [30, 31]. The resulting steryl esters are then deposited into intracellular lipid particles from where they can be mobilized by three different steryl ester hydrolases: Yeh1, Yeh2 and Tgl1 [32].

Saccharomyces cerevisiae does not take up exogenous sterol under aerobic conditions, but cells are sterol auxotroph in the absence of oxygen or if they are not able to synthesize heme [33, 34]. The molecular basis for the exclusion of sterols under aerobic conditions is not well understood, but it can partially be overcome by expression of a hypermorphic allele of the transcription factor UPC2 or by overexpression of the transcriptional regulator SUT1 [35, 36]. Aerobic uptake of sterols in the UPC2-1 mutant appears to be mediated by upregulation of two ABC transporters, PDR11 and AUS1, and a putative cell wall protein, Dan1[37, 38]. Consistent with a role of the two ABC transporters in sterol uptake, a $p d r 11 \Delta$ aus $1 \Delta$ 
double mutant does not grow under anaerobic conditions and the double mutant has a greatly reduced rate of steryl ester formation [37, 39]. A defect in sterol uptake and impaired growth under anaerobic conditions was also observed in cells that lack $A R V 1$, a gene that is required for viability of cells that lack steryl esters [40]. $A R V 1$ encodes a conserved protein with 6 putative transmembrane domains and localizes to the endoplasmic reticulum and Golgi membranes [41]. In addition to their defect in sterol uptake, arv1 $1 \Delta$ mutants have pleiotropic defects in sphingolipids, phospholipids and sterol metabolism [41].

\section{A screen for sterol uptake and transport mutants}

We became interested in sterol trafficking because we isolated mutants in the sterol biosynthetic pathway as being synthetic lethal with mutants in fatty acid elongation. Subsequent work then showed that the combination of defects in certain sterol modifications with defects in sphingolipid synthesis affects raft association and the stability of integral membrane proteins [42]. These and the observations made by others (see above) indicate that sterol trafficking is intimately related to sphingolipid metabolism in yeast and mammalian cells.

In an $a b$ initio approach to identify genes that are involved in sterol trafficking, we screened the yeast deletion mutant collection for genes that are required for growth under anaerobic conditions. Of approximately 37 mutants isolated in this screen, 16 affected sterol uptake and/or trafficking as assessed by genetic and biochemical analyses. When combined with mutations in hem 1, these strains failed to grow on media containing sterols (ergosterol or cholesterol) and unsaturated fatty acids. The lack of HEMI can either be overcome by supplementing cells with sterols and unsaturated fatty acids or can be bypassed by supplementing the cells with delta- 
aminolevulinic acid, the enzymatic product of the first step in hem biosynthesis catalyzed by Hem1 [43]. Importantly, all of these uptake mutants grew normally if the block imposed by hem 1 is bypassed by the addition of delta-aminolevulinic acid to the media, which is consistent with a defect in lipid uptake/trafficking (Figure 1). When incubated with $\left[{ }^{14} \mathrm{C}\right]$-cholesterol, the mutants failed to take up the label and they showed no or greatly reduced levels of radiolabeled free and esterified cholesterol (Figure 2). Incubations with $\left[{ }^{3} \mathrm{H}\right]$-palmitate, however, indicate that these mutants have no defects in fatty acid uptake and incorporation of exogenous fatty acids into lipids (Reiner et al., manuscript submitted). Furthermore, the sterol transport defect in these mutants could be visualized using a fluorescent cholesterol derivative, NBDcholesterol [44, 45]. Heme-deficient wild-type cells incubated with NBD-cholesterol displayed intense staining of the plasma membrane and staining of intracellular lipid particles. The sterol uptake mutants, on the other hand, showed no or only little staining of the plasma membrane and the intracellular lipid particles (Figure 3).

Taken together, the results of this screen for sterol uptake and transport mutants in yeast revealed 16 genes that are required for growth under anaerobic conditions and for the efficient uptake of cholesterol. Aim of future studies now is to characterize the sterol trafficking defect of these mutants in more detail and to understand the role of the respective genes in the putative sterol transport pathway. Results of such studies are likely to be relevant for the pathology of certain human lipid storage diseases and to understand sterol homeostasis at a cellular level. 


\section{References}

$1 \quad$ Keller, P. and Simons, K. (1998) J. Cell Biol. 140, 1357-1367

2 Willemsen, V., Friml, J., Grebe, M., van den Toorn, A., Palme, K. and Scheres, B. (2003) Plant Cell 15, 612-625

3 Umebayashi, K. and Nakano, A. (2003) J. Cell Biol. 161, 1117-1131

4 Liscum, L. and Dahl, N. K. (1992) Journal of Lipid Research 33, 1239-1254

$5 \quad$ Maxfield, F. R. and Wustner, D. (2002) J. Clin. Invest. 110, 891-898

6 Soccio, R. E. and Breslow, J. L. (2004) Arterioscler. Thromb. Vasc. Biol. 24, $1150-1160$

7 Lange, Y., Swaisgood, M. H., Ramos, B. V. and Steck, T. L. (1989) J. Biol. Chem. 264, 3786-3793

8 DeGrella, R. F. and Simoni, R. D. (1982) J. Biol. Chem. 257, 14256-14562

9 Urbani, L. and Simoni, R. D. (1990) J. Biol. Chem. 265, 1919-1923

10 Kaplan, M. R. and Simoni, R. D. (1985) J. Cell Biol. 101, 446-453

11 Heino, S., Lusa, S., Somerharju, P., Ehnholm, C., Olkkonen, V. M. and Ikonen, E. (2000) Proc. Natl. Acad. Sci. USA 97, 8375-8380

12 Brown, M. S. and Goldstein, J. L. (1986) Science 232, 34-47

13 Brown, M. S., Ho, Y. K. and Goldstein, J. L. (1980) J. Biol. Chem. 255, 93449352

14 Brasaemle, D. L. and Attie, A. D. (1990) J. Lipid Res. 31, 103-112

15 Johnson, W. J., Chacko, G. K., Phillips, M. C. and Rothblat, G. H. (1990) J. Biol. Chem. 265, 5546-5553

16 Neufeld, E. B., Cooney, A. M., Pitha, J., Dawidowicz, E. A., Dwyer, N. K., Pentchev, P. G. and Blanchette-Mackie, E. J. (1996) J. Biol. Chem. 271, 21604-21613

17 Lange, Y., Ye, J. and Chin, J. (1997) J. Biol. Chem. 272, 17018-17022

18 Underwood, K. W., Jacobs, N. L., Howley, A. and Liscum, L. (1998) J. Biol. Chem. 273, 4266-4274 
19 Roff, C. F., Goldin, E., Comly, M. E., Cooney, A., Brown, A., Vanier, M. T., Miller, S. P., Brady, R. O. and Pentchev, P. G. (1991) Dev. Neurosci. 13, 315319

20 Butler, J. D., Blanchette-Mackie, J., Goldin, E., O'Neill, R. R., Carstea, G., Roff, C. F., Patterson, M. C., Patel, S., Comly, M. E., Cooney, A., Vanier, M. T., Brady, R. O. and Pentchev, P. G. (1992) J. Biol. Chem. 267, 23797-23805

21 Lange, Y. and Steck, T. L. (1994) J. Biol. Chem. 269, 29371-29374

22 Skiba, P. J., Zha, X., Maxfield, F. R., Schissel, S. L. and Tabas, I. (1996) J. Biol. Chem. 271, 13392-13400

23 Sokol, J., Blanchette-Mackie, J., Kruth, H. S., Dwyer, N. K., Amende, L. M., Butler, J. D., Robinson, E., Patel, S., Brady, R. O., Comly, M. E., Vanier, M. T. and Pentchev, P. G. (1988) J. Biol. Chem. 263, 3411-3417

24 Pentchev, P. G., Vanier, M. T., Suzuki, K. and Patterson, M. C. (1995) in Metabolic and Molecular Bases of Inherited Disiease (Scriver, C. R.. Beaudet, A. L., Sly, W. S., and Valle, D., eds), pp. 2625-2639, McGraw Hill, New York

25 Ioannou, Y. A. (2001) Nat. Rev. Mol. Cell Biol. 2, 657-668

26 Feng, B., Yao, P. M., Li, Y., Devlin, C. M., Zhang, D., Harding, H. P., Sweeney, M., Rong, J. X., Kuriakose, G., Fisher, E. A., Marks, A. R., Ron, D. and Tabas, I. (2003) Nat. Cell Biol. 5, 781-792

27 Sturley, S. L. (1998) Cur. Opin. Lipidol. 9, 85-91

28 Sturley, S. L. (2000) Biochim. Biophys. Acta 1529, 155-163

29 Lees, N. D., Bard, M. and Kirsch, D. R. (1999) Crit. Rev. Biochem. Mol. Biol. 34, 33-47

30 Yu, C., Kennedy, N. J., Chang, C. C. and Rothblatt, J. A. (1996) J. Biol. Chem. 271, 24157-24163

31 Yang, H., Bard, M., Bruner, D. A., Gleeson, A., Deckelbaum, R. J., Aljinovic, G., Pohl, T. M., Rothstein, R. and Sturley, S. L. (1996) Science 272, 13531356

32 Köffel, R., Tiwari, R., Falquet, L. and Schneiter, R. (2005) Mol. Cell. Biol. 25, 1655-1668. 
33 Lorenz, R. T. and Parks, L. W. (1991) Lipids 26, 598-603

34 Lorenz, R. T., Rodriguez, R. J., Lewis, T. A. and Parks, L. W. (1986) J. Bacteriol. 167, 981-985

35 Lewis, T. L., Keesler, G. A., Fenner, G. P. and Parks, L. W. (1988) Yeast 4, 93-106

36 Bourot, S. and Karst, F. (1995) Gene 165, 97-102

37 Wilcox, L. J., Balderes, D. A., Wharton, B., Tinkelenberg, A. H., Rao, G. and Sturley, S. L. (2002) J. Biol. Chem. 277, 32466-32472

38 Alimardani, P., Regnacq, M., Moreau-Vauzelle, C., Ferreira, T., Rossignol, T., Blondin, B. and Berges, T. (2004) Biochem. J. 381, 195-202

39 Li, Y. and Prinz, W. A. (2004) J. Biol. Chem. 279, 45226-45234

40 Tinkelenberg, A. H., Liu, Y., Alcantara, F., Khan, S., Guo, Z., Bard, M. and Sturley, S. L. (2000) J. Biol. Chem. 275, 40667-40670.

41 Swain, E., Stukey, J., McDonough, V., Germann, M., Liu, Y., Sturley, S. L. and Nickels, J. T., Jr. (2002) J. Biol. Chem. 277, 36152-36160

42 Eisenkolb, M., Zenzmaier, C., Leitner, E. and Schneiter, R. (2002) Mol. Biol. Cell 13, 4414-4428

43 Gollub, E. G., Liu, K. P., Dayan, J., Adlersberg, M. and Sprinson, D. B. (1977) J. Biol. Chem. 252, 2846-2854

44 Mukherjee, S. and Chattopadhyay, A. (1996) Biochemistry 35, 1311-1322

45 Sparrow, C. P., Patel, S., Baffic, J., Chao, Y. S., Hernandez, M., Lam, M. H., Montenegro, J., Wright, S. D. and Detmers, P. A. (1999) J. Lipid Res. 40, 1747-1757 


\section{Figure legends}

Figure 1. Growth of anaerobic non-viable mutants in a heme-deficient background.

Heme-deficient wild-type and uptake mutant cells were 10 -fold serially diluted and spotted on YPD media containing cholesterol (Chol/Tw) or ergosterol (Erg/Tw) and Tween 80 as a source for unsaturated fatty acids, YPD media containing deltaaminolevulinic acid (ALA), and on non-supplemented YPD media (Non-suppl.). Plates were incubated under aerobic conditions for 4 days at $30^{\circ} \mathrm{C}$.

Figure 2. Uptake and esterification of $\left[{ }^{14} \mathrm{C}\right]$-cholesterol.

Heme-deficient wild-type and uptake mutant cells were grown in the presence of $\left[{ }^{14} \mathrm{C}\right]$-cholesterol and Tween 80 for $48 \mathrm{~h}$ at $24^{\circ} \mathrm{C}$. Equal OD units of cells were harvested, lipids were extracted, separated by TLC, and $\left[{ }^{14} \mathrm{C}\right]$ cholesterol in the free and esterified sterol fraction was quantified by radio scanning.

Figure 3. Subcellular localization of NBD-cholesterol.

Heme-deficient wild-type and uptake mutant cells were grown in the presence of NBD-cholesterol for $24 \mathrm{~h}$ at $24^{\circ} \mathrm{C}$ and NBD-cholesterol localization was examined by fluorescent microscopy using identical exposure settings. Plasma membrane and lipid particle staining is indicated by arrows and arrowheads, respectively. Nomarski view of the same visual field is shown below. Bar, $5 \mu \mathrm{m}$. 


\begin{tabular}{|c|c|c|c|c|}
\hline & Chol/Tw & $\mathrm{Erg} / \mathrm{Tw}$ & ALA & Non-suppl. \\
\hline
\end{tabular}

Figure 1 


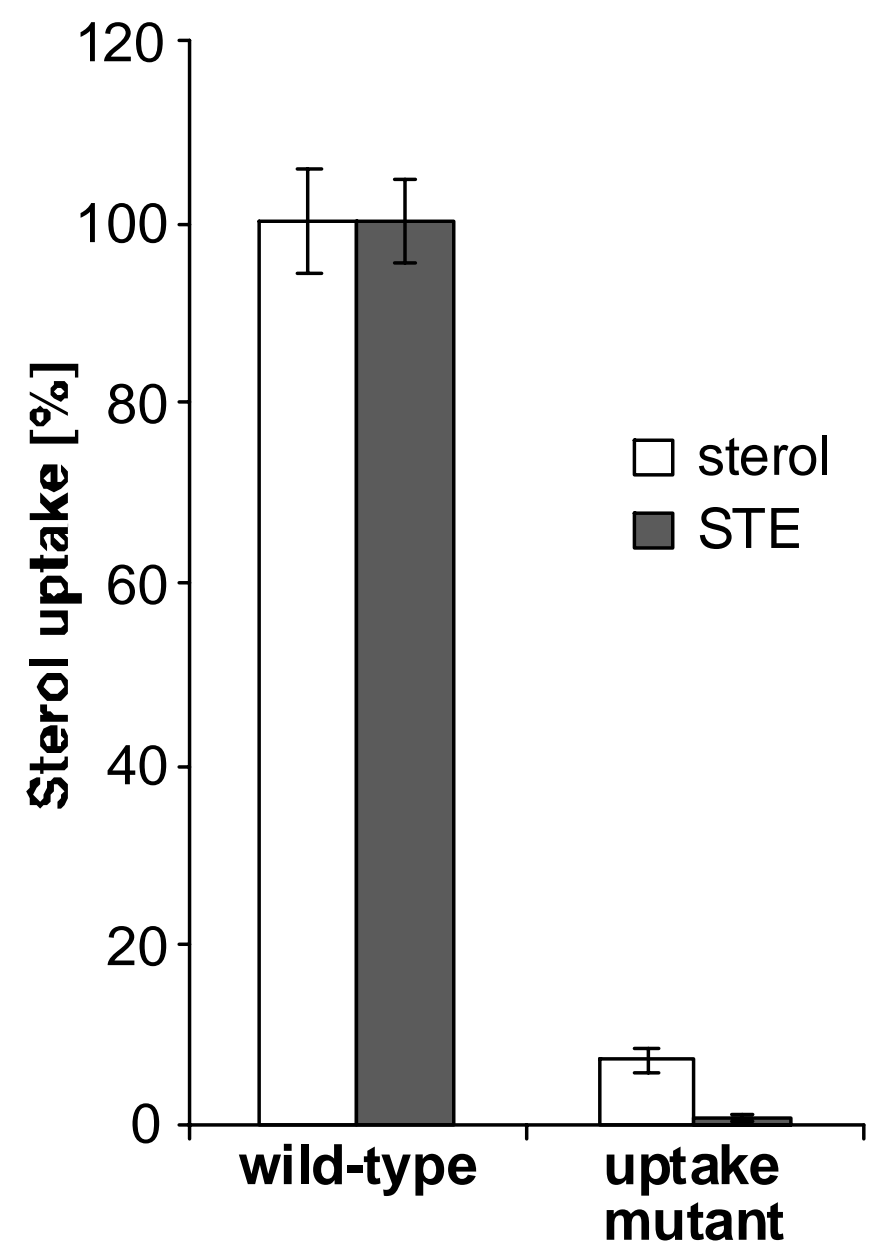

Figure 2 




Figure 3 